\title{
Does Foreign Direct Investment really affect Ghana's Economic Growth?
}

\section{Gabriel Obed Fosu', Eric Amoo Bondzie ${ }^{2}$, Gabriel Asare Okyere ${ }^{3}$}

Department of Mathematics, Kwame Nkrumah University of Science and Technology, Kumasi, Ghana $^{1,3}$

DEFAP, Università Cattolica del Sacro Cuore, Italy ${ }^{2}$

Emails: gabrielobedpeters@gmail.com ${ }^{1}$,EricAmoo.Bondzie@unicatt.it ${ }^{2}$, goasare@yahoo.co.uk ${ }^{3}$

DOI: 10.6007/IJAREMS/v3-i1/602 URL: http://dx.doi.org/10.6007/IJAREMS/v3-i1/602

\begin{abstract}
In this paper, we investigate the linkage between FDI and economic growth using macro econometric model in the Ghanaian context. Structural shocks in an SVAR model were used to identify the contemporaneous and short run relationships effects of these variables. The $A B$ model restriction approach was used for the Identification and was compared to the Cholesky decomposition. We showed that, there exit a contemporaneous short run positive effects of FDI inflows on GDP growth but as the time horizon expands these effects tend to converge to the equilibrium, however FDI's deteriorate domestic investment.
\end{abstract}

Keywords: Foreign direct investment, Gross domestic product, Impulses Responses, Structural VAR

\section{Introduction}

The economic progress of countries depends to a large extent on the opportunity of making profitable investments and accumulating capital. Having access to foreign capital and investments allows a country to invest in both human and physical capital and to exploit opportunities that otherwise could not be used. Beginning from a general mistrust of foreign direct investment (FDI) in the 1960s and early 1970s, developing country governments have now come to embrace it warmly within the last two decades. The growing interest in FDI is not only a result of globalization but also a consequence of the steady decline in official development assistance. Developing country share of FDI has increased from a paltry $5 \%$ in 1980 to $36 \%$ in 2004 (UNCTAD, 2008). Foreign direct investment is now viewed as a source of capital and a major tool in the fight against poverty. It is also viewed as a catalyst for technology transfer from the developed to developing countries. It is known from economic theory that, international capital inflows, inter alia, promote efficient allocation of resources, which in turn enhances economic growth (Asafu-Adjaye 2005). There is a widespread belief that foreign direct investment (FDI) enhances the productivity of host countries and promotes economic development. FDI may not only provide direct capital financing but also create positive externalities via the adoption of foreign technology and know-how. A country's capacity to take advantage of FDI externalities might be limited by local conditions, such as the development of 
local financial markets (Alfaro 2009). Alfaro et al. (2004) provide evidence that only countries with well-developed financial markets gain significantly from FDI in terms of their growth rates. In this paper we ascertain the nexus between FDI and economic growth in the Ghanaian context within the broader increasingly competitive world market for FDI based on macro econometric modeling. We identify the contemporaneous and short run relationships effects of these variables using Structural shocks in an SVAR model. We further find out the impact of FDI on other economic variables like Inflation, Gross Fixed Capital Formation as well as Government Expenditure.

There is a vast body of empirical literature: Azmat (1999), Andrea Marino (2000), Balasundram (2000), Kishor (2000), Chakrabarti (2001), Gordon (2001), on whether foreign direct investment is beneficial to host country's growth or not. Trade theorist believes, market size, trade policy regime followed by host countries development policies influences significantly both the amount of inward FDI received by recipient countries and the impact of foreign direct investment on growth. With respect to the Ghanaian economy, Okyere, Fosu and Boakye (2014) examined the causality of macroeconomic variables using multivariate vector autoregressive model. Antwi and Zhao (2013) applied the cointegration method to determine how FDI, GDP and Gross National Income (GNI) are related. The study established a long-run equilibrium and causal relationship between these variables. But in the short-run, the effects of GDP and GNI volatility on FDI are nearly imaginary. Baba Insah (2013) also investigated the relationship between economic growth and FDI inflows using Dynamic Ordinary Least Squares (DOLS) technique. He indicated that, the elasticity of economic growth with respect to FDI had a positive sign. However, the effect of a three year lag of FDI on economic growth had a negative sign.

\section{Methodology}

This study used the Vector Autoregressive (VAR) model. Under the VAR model methodologies, the relationships of the variables were determined with their optimal lag length effects. The Causality was determined based on one-way causality or either direction techniques suggested by Engle and Granger (1987). These techniques were accompanied with the impulse response functions and the variance decomposition functions. The standard procedure of using both techniques to measure the change in one of the variable and keeping all other variables constant and finding the covariance matrix of the reduce form residuals was to orthogonalize the innovations. The technique gave us the forecasting capability of each of the variables defining to the other variables. The necessary model checking and identification procedure was applied for the suitability of the model, optimal lag lengths based on criterion used by the FPE (Final Prediction Error), AIC (Akakai's information Criterion). Structural shocks in a SVAR model was identified by placing some restrictions on contemporaneous and short run relationships. With this, the $A B$ model of Amisano and Giannini (1997) restriction approach was used for the Identification and later compared to the Cholesky decomposition. The unit roots and order of the integration of the variables using Augmented Dickey Fuller (ADF) and Phillips-Person tests were applied. 


\section{The Model}

To capture the relationship between GDP and FDI inflows, a simple model by Matthias Busse (2003) in his analysis of democracy and FDI was adopted and modified to suit the peculiarities of Ghana as:

$$
G D P=f(F D I, v)
$$

where GDP is a function of policy distortions (FDI) and $v$ control variables that can impact GDP growth overtime. The model was linearized for estimation as:

$G D P=b_{0}+b_{1} G E+b_{2} G F C F+b_{3} C P I+b_{4} F D I+\epsilon_{t}$

Where GE is Government Expenditure, GFCF is Gross Fixed Capital Formation and CPI is Consumer Price Index as a measure of inflation. The linear specification of the model might be questioned, however, Chakrabarti (2001), has confirmed that in country-specific analysis, modeling FDI determinants in semi-log form can improve the overall fit and the significance of the coefficients. To ensure that the predictive power of the model is unquestionable a battery of tests for the normality of residuals, homoscedasticity of errors, serial correlation and structural stability were run to support the empirical results.

\section{Structural VAR}

The basic form of a vector autoregressive model of order $k$ is described by (Lutkepohl, 1993 \& 2003):

$x_{t}=\mu_{t}+\sum_{i=1}^{k} A_{i} x_{t-i}+u_{t}$

where $x_{t}=\left(x_{1 t}, x_{2 t}, \cdots, x_{p t}\right)^{\prime}$ is a $(p \times 1)$ vector of endogenous variable. $u_{t}$ is a $k$-dimensional process with $E\left(u_{t}\right)=0$ and time invariant positive covariance matrix $E\left(u_{t} u_{t}^{T}\right)=\Sigma_{u}$ (white noise). The impulse responses functions $\Phi$ are calculated from the moving average representation of the VAR

$x_{t}=\sum_{i=0}^{\infty} \Phi_{i} u_{t-i}$

The contemporaneous relationships between the variables can be included into the model by transforming the VAR model (1) into the structural vector autoregressive (SVAR) model (Hamilton, 1994):

$A x_{t}=\sum_{i=1}^{k} A_{i}^{*} x_{t-i}+B \epsilon_{t}$

where the structural errors $\epsilon_{t}$, are white noise and $A_{i}^{*}$ are the structural coefficient matrices. The reduced form of the SVAR is given as

$$
\begin{gathered}
x_{t}=A^{-1} \sum_{i=1}^{k} A_{i}^{*} x_{t-i}+A^{-1} B \epsilon_{t} \\
x_{t}=A^{-1} \sum_{i=1}^{k} A_{i}^{*} x_{t-i}+u_{t}
\end{gathered}
$$


The recursive form is equation one is given as:

$$
\begin{aligned}
& A(L) x_{t}=u_{t} \\
& A(L)=1-\sum_{i=1}^{k} A_{i} L^{i}=I_{p}-A_{1} L-\cdots-A_{k} L^{k}
\end{aligned}
$$

where $L$ denotes the Lag operator $L^{i} x_{t}=x_{t-i}$, and $I_{p}$ is a $p$ dimensional identity matrix. The $A B$ model by Amisano and Giannini is obtained by multiplying (7) by $A$ and assuming that $A u_{t}=B e_{t}$. Thus

$$
A A(L) x_{t}=B e_{t}, \quad e_{t} \sim N\left(0, I_{p}\right)
$$

Given that $P$ is a triangular matrix, the Cholesky decomposition is calculated as

$$
A=P^{\prime} \quad \text { and } \quad \Sigma_{u}=P P^{\prime}
$$

\section{Discussion of Results}

Annual time series data covering the period 1975-2010 were obtained from World Bank's World Development Indicators 2012. These were transformed to quarterly data with 144 observations by EViews software packages.

This study looked beyond the traditional regression problems of autocorrelation, multicollinearity and simultaneity and considered the dynamic specification of the series. Unit root tests suggest that almost all of the variables included in the model are non-stationary at levels. Johansen cointergration test was carried out, and the results are indicated in Table 4 of the Appendix. The Johansen test indicates the presence of one co-integrating vector at lag 2 but statistical checking proved that the co-integrating vector is not statistically significant. To capture best impulse response and variance decomposition results; a lag structure of 2, as suggested by Akaike, Schwarz and Hannan-Quinn information criterion was specified for the explanatory variables and gradually reduced to the parsimonious model. For numerical illustration see Table 5 .

The $A B$ model of Amisano and Giannini suggests that the restrictions are to be placed on the matrix $A$ and matrix $B$ should be a diagonal matrix. Theoretical evidence to support this restriction is inadequate therefore these restrictions were done based on empirical findings. The series of matrix restrictions and changes being made in the lag order the matrix equation below represents the restrictions being imposed for proper impulse response and variance decomposition.

Table 1: Matrix A restriction of the AB model:

$\begin{array}{llllll} & \text { GDP shock } & \text { GE shock } & \text { GFCF shock } & \text { CPI shock } & \text { FDI shock } \\ \text { GDP } & 1 & 0 & 0 & \text { N/A } & \text { N/A } \\ \text { GE } & \text { N/A } & 1 & 0 & 0 & 0 \\ \text { GFCF } & \text { N/A } & \text { N/A } & 1 & \text { N/A } & 0 \\ \text { CPI } & 0 & \text { N/A } & 0 & 1 & \text { N/A } \\ \text { FDI } & 0 & \text { N/A } & \text { N/A } & 0 & 1\end{array}$


The above restrictions were imposed on the matrix $A$ of the $A B$ model and the results are shown in Table 2 . These restrictions give statistically significant co-efficients and the proper impulse response and variance decomposition functions. The N/A coefficients in the matrix equation indicate that the shocks in column variable affect its corresponding row variable. The zero coefficients indicate that those entries in the matrix are constrained to be zero.

The results of ADF unit root tests on the GDP growth and FDI in their log-levels and logdifferenced forms indicate that, real GDP growth and FDI ratio are non-stationary in their respective levels. Then again, after first differencing the variables, the null hypothesis of a unit root in the ADF tests were rejected at the $5 \%$ significance level for all the series. Thus the series are integrated of order one, I (1). Moreover AIC, SBC and Likelihood Ratio (LR) information criteria established the optimum lag length of the VAR. Table 5 presents the output of the choice criteria for selecting the order of the VAR model. The Adjusted LR test statistics adjusted for the samples rejects the zero lag. On the basis of the results, the LR, FPE and AIC selects 6 lags and the SBC selects 2 lag. The minimized SBC's two (2) lag order for the VAR model is selected because it captures best impulse response and variance decomposition results.

Table 2: Results Of Matrix A Restriction Of The AB Model

\begin{tabular}{lllll}
\hline \hline$A=$ & & & & \\
1 & & & & \\
$C(1)$ & 1 & 0 & 0 & 0 \\
$C(2)$ & $C(3)$ & 1 & $C(8)$ & 0 \\
0 & $C(4)$ & 0 & 1 & $C(10)$ \\
0 & $C(5)$ & $C(6)$ & 0 & 1 \\
$B=$ & & & & \\
$C(11)$ & 0 & 0 & 0 & 0 \\
0 & $C(12)$ & 0 & 0 & 0 \\
0 & 0 & $C(13)$ & 0 & 0 \\
0 & 0 & 0 & $C(14)$ & 0 \\
0 & 0 & 0 & 0 & $C(15)$ \\
\hline \hline & & & & \\
\hline & & & & \\
$C(1)$ & -0.770768 & 0.068416 & -11.26586 & 0.0000 \\
$C(2)$ & -0.520218 & 0.226069 & -2.301146 & 0.0214 \\
$C(3)$ & -0.352901 & 0.177454 & -1.988691 & 0.0467 \\
$C(4)$ & -0.280162 & 0.501029 & -0.559174 & 0.5760 \\
$C(5)$ & 1.161884 & 0.493474 & 2.354499 & 0.0185 \\
$C(6)$ & -1.464532 & 0.377356 & -3.881037 & 0.0001 \\
$C(7)$ & -0.000264 & 0.026160 & -0.010083 & 0.9920 \\
$C(8)$ & -0.159559 & 0.049376 & -3.231509 & 0.0012 \\
$C(9)$ & -0.018290 & 0.033566 & -0.544890 & 0.5858 \\
$C(10)$ & 0.747677 & 0.148895 & 5.021512 & 0.0000 \\
$C(11)$ & 0.010438 & 0.000627 & 16.65447 & 0.0000 \\
$C(12)$ & 0.008345 & 0.000495 & 16.85141 & 0.0000 \\
& & & &
\end{tabular}




\begin{tabular}{lllll}
$C(13)$ & 0.017352 & 0.001300 & 13.35232 & 0.0000 \\
$C(14)$ & 0.049318 & 0.003278 & 15.04332 & 0.0000 \\
$C(15)$ & 0.044390 & 0.003090 & 14.36337 & 0.0000 \\
\hline
\end{tabular}

Figure 5 represents the impulse responses as a result of a shock in FDI. It shows that a shock or an inward flow of FDI corresponds to contemporaneous increase in Gross Domestic Product, Government Expenditure and lowers the Gross Fixed Capital Formation. This result follows the various empirical literatures presented on FDI and economic growth as well as no positive improvements in GFCF. The figure also depicts that foreign investors are sensitive to the levels of inflation. This is because as FDI increases within the first-five quarter the inflation levels are at its minimal and as inflation rises FDI reduces.

Because we seek to find the relationship among GDP growth and FDI, a shock in GDP was imposed to see its effects. There is no contemporaneous effect of growth in GDP on FDI. But rather as time goes on this shock in GDP turns to increase the inflow of FDI. Figure 1 indicates that inflation is a sensitive phenomenon which needs to be addressed since it influences the decision of both foreign and domestic investment.

Response to Structural One S.D. Innovations \pm 2 S.E.
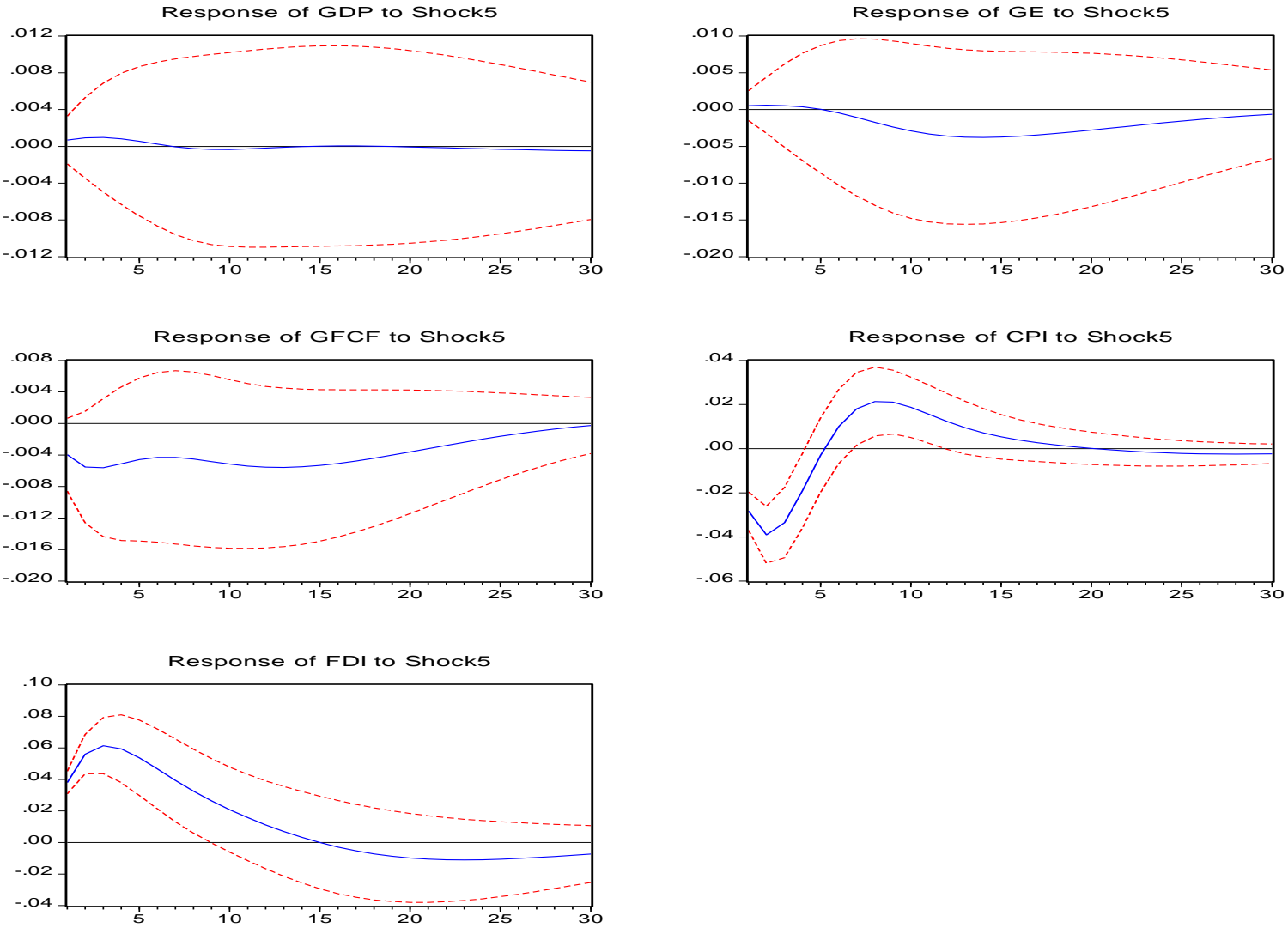

Figure 1: Responses to FDI Shocks

Therefore the Ghanaian economy needs to tackle the issue of inflation to attract a sizable FDI. The variance decomposition shows the variation explained by the other variables to the policy 
variables. There is a huge variation in both FDI and GDP shocks; this is due to fact that the Ghanaian economy is linked strongly to FDI. This is illustrated in Figure 3.We further compared the Cholesky decomposition and the $A B$ model. As shown in Figure 4, the Cholesky Decomposition gives an impulse model which deviates from the various theoretical and empirical evidences of GDP growth and FDI inflows relation. This is because the Cholesky Decomposition indicates that the relation between these two variables is negative whiles most literatures suggest otherwise. This argument concludes that the $A B$ Model of Amisano and Giannini will be the best model to use to describe the Ghanaian economy.

Response to Structural One S.D. Innovations \pm 2 S.E.
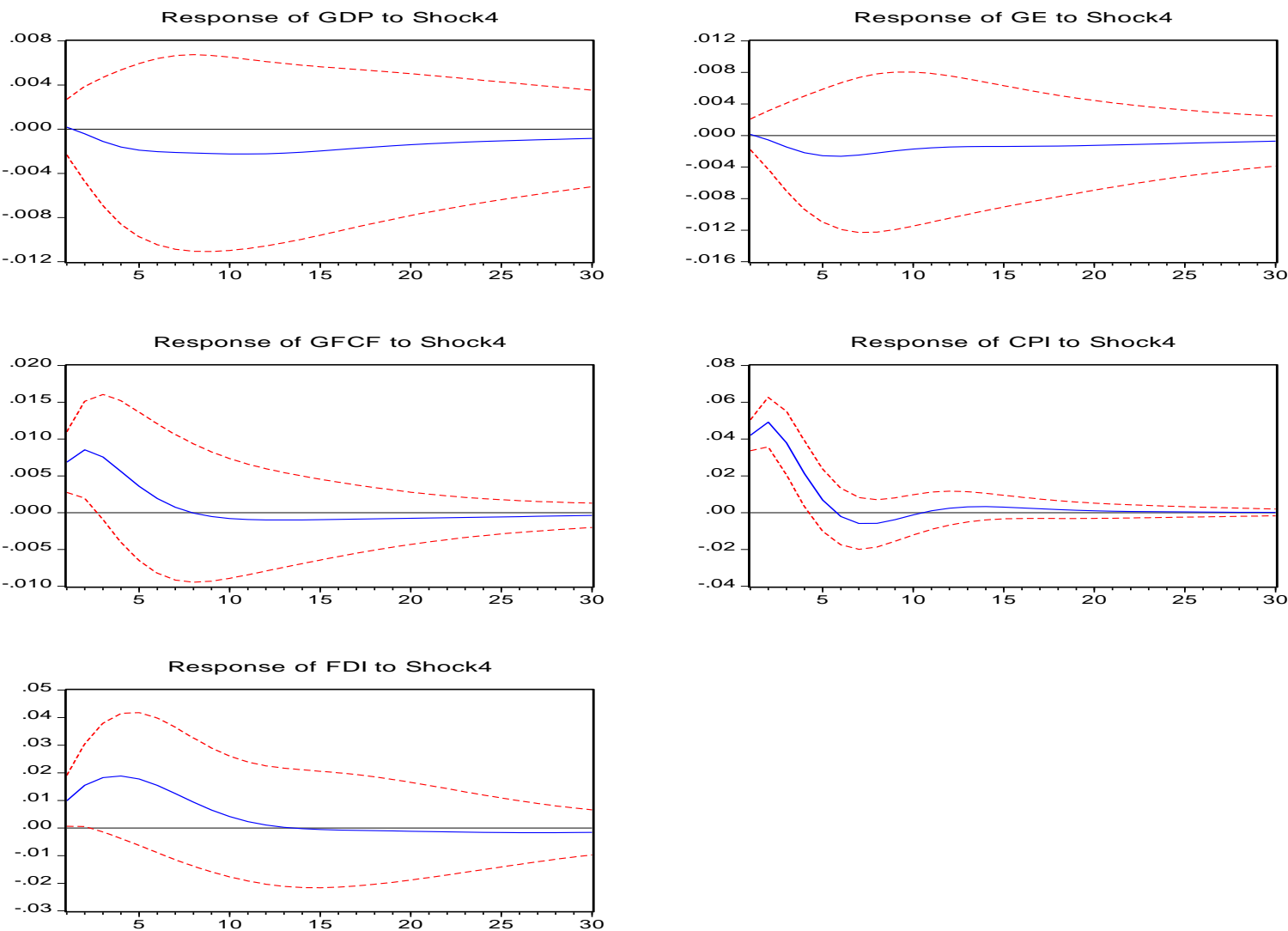

Figure 2: Responses to CPI Shocks: 

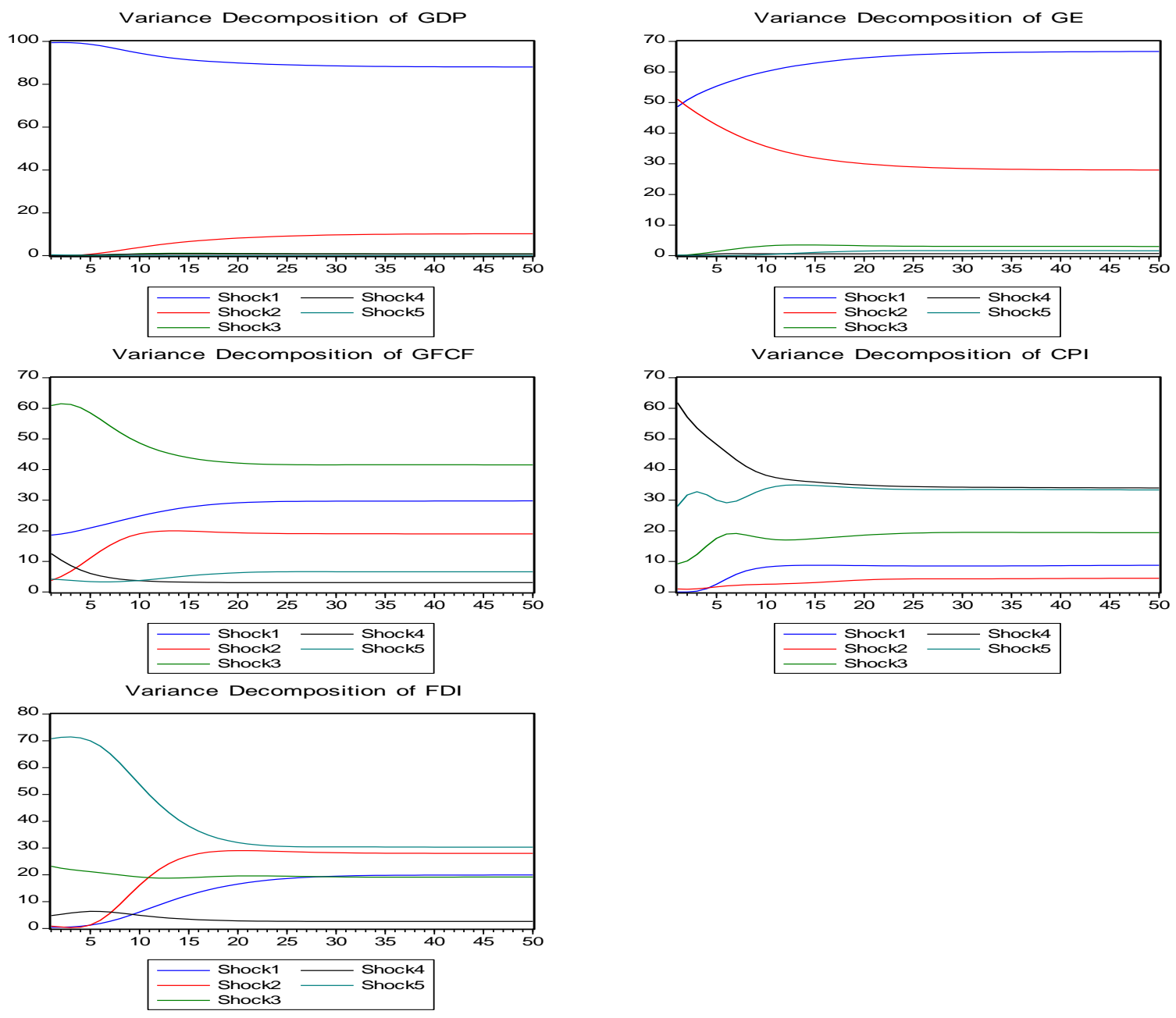

Figure 3: Combined Variance Decomposition:

\section{Conclusion}

In this paper we have demonstrated that foreign direct investment correlates with economic growth in Ghana. Using Amisaso amd Giannini restrictions, the model suggests that there exit contemporaneous short run positive effects of FDI inflows on GDP growth. However, as the time horizon expands, these effects tend to converge to the equilibrium. This research also indicates that inflation (CPI) influences the inflow of FDI into the country and therefore needs to be given a closer attention.

\section{References}

Alfaro, L. and Rodriguez-Clare, A. (2004). Multinationals and Linkages: Evidence from Latin America. Economia 4, 113-170.

Alfaro, L., Chanda, A., Kalemli-Ozcan, S., and Sayek, S. (2004). FDI and Economic Growth, The Role of Local Financial Markets. Journal of International Economics 64, 113-134. 
Amisano, G. and Giannini, C. (1997). Topics in Structural VAR Econometrics, Second edition. Springer, Berlin.

Andrea Marino (2000). The impact of FDI on developing countries growth: Trade policy matters. ISTAT (National Institute of Statistics), Italy. CEMAFI, Université de Nice-Sophia Antipolis, France.

Asafu-Adjaye, J. (2005). What has been the Impact of Foreign Direct Investment in Ghana? The Institute of Economic Affairs Publications Vol 1.

Azmat Ghani (1999). Foreign Direct Investment in Fiji'.Pacific economic bulletin, volume 14, number 1, June 1999 Asia Pacific Press.

Baba Insah (2013). Foreign Direct Investment Inflows and Economic Growth in Ghana. International Journal of Economic Practices and Theories, Vol. 3, No. 2, 2013.

Balasundram Maniam (2000). U.S. FDI in Latin America: A new perspective. Sam Houston State University Proceedings of the Academy for Economics and Economic Education, 3(2)

Chakrabarti, A. (2001). The Determinants of Foreign Direct Investment: Sensitivity Analyses of Cross-Country Regressions, Kyklos, 54(1):89-113

Engle, F. and Granger, C. (1987). Cointegration and Error Correction: Representation, Estimation and Testing. Econometrica 55: 251-76

Gordon H. Hanson (2001). Should Countries Promote Foreign Direct Investment? United Nations Conference on Trade and Development- Center for International Development Harvard University. Research papers for the Intergovernmental Group of Twenty-Four on International Monetary Affairs.

Johanson S. (1995). Likelihood-Based Inference in Cointegrated Vector Autoregressive Models. New York: Oxford University Press.

Hamilton, J. D. (1994). Time series analysis. Princeton: Princeton University Press.

Kishor Sharma (2000). Export Growth In India: Has FDI Played A Role' Center Discussion Paper No. 816 Charles Stuart University Australia.

Lutkepohl, H. (1993). Introduction to multiple times series analysis. Second edition, Berlin: Springer.

Lutkepohl, H. (2001). Vector autoregressions. In Baltagi, B. (Ed.) Companion to theoretical econometrics, Oxford: Blackwell, 678-699. 
Matthias, B. (2003). Democracy and FDI, Hwwa Discussion Paper 220 Hamburgisches WeltWirtschafts Archives.

Okyere, G. A., Fosu, G. O. and Boakye R. O. (2014). Granger Causality Analysis of Some Macroeconomic Variables in Ghana. Journal of Research in Business and Management, Volume 2, Issue 1, 09-17

Antwi, S. and Zhao, X. (2013). Impact of Foreign Direct Investment and Economic Growth in Ghana: A Cointegration Analysis. International Journal of Business and Social Research, Volume -3, No.-1.

UNCTAD (2008), Foreign Direct Investment Database (online), Internet Posting: http://www.unctad.org/Templates/Page.asp?intltemID=1923\&lang=1.

\begin{tabular}{|c|c|c|c|c|c|}
\hline & \multicolumn{5}{|c|}{$\begin{array}{c}\text { Appendix } \\
\text { Table } 3 \text { Correlation Matrix: }\end{array}$} \\
\hline & GDP & GE & GFCF & $\mathrm{CPI}$ & FDI \\
\hline GDP & 1 & & & & \\
\hline GE & 0.95907 & 1 & & & \\
\hline GFCF & 0.89044 & 0.93406 & 1 & & \\
\hline $\mathrm{CPI}$ & -0.60903 & -0.61201 & -0.67233 & 1 & \\
\hline FDI & 0.77892 & 0.83918 & 0.84939 & -0.50934 & 1 \\
\hline
\end{tabular}

Table 4: Johansen Co-Integration Test

\begin{tabular}{llllll}
\hline \hline Data Trend: & None & None & Linear & Linear & Quadratic \\
\hline \multirow{4}{*}{ Test Type } & No & & & & \\
& Intercept & Intercept & Intercept & Intercept & Intercept \\
Trace & No Trend & No Trend & No Trend & Trend & Trend \\
Max-Eig & 1 & 1 & 1 & 1 & 2 \\
\hline \hline
\end{tabular}

*Critical values based on MacKinnon-Haug-Michelis (1999)

Table 5: Lag Length Selection

\begin{tabular}{lllllll}
\hline \hline Lag & LogL & LR & FPE & AIC & SC & HQ \\
\hline \hline 0 & 703.0791 & NA & $2.58 \mathrm{e}-11$ & -10.19234 & -9.978174 & -10.10531 \\
1 & 1602.429 & 1706.120 & $6.72 \mathrm{e}-17$ & -23.05043 & -22.30085 & -22.74582 \\
2 & 1731.696 & 235.7217 & $1.45 \mathrm{e}-17$ & -24.58376 & $-23.29877^{*}$ & -24.06157 \\
3 & 1745.938 & 24.92371 & $1.71 \mathrm{e}-17$ & -24.42556 & -22.60515 & -23.68579 \\
4 & 1751.492 & 9.310753 & $2.29 \mathrm{e}-17$ & -24.13959 & -21.78376 & -23.18224 \\
5 & 1850.566 & 158.8100 & $7.81 \mathrm{e}-18$ & -25.22891 & -22.33767 & -24.05398
\end{tabular}




$\begin{array}{lllllll}6 & 1915.103 & 98.70404^{*} & 4.44 \mathrm{e}-18 * & -25.81034 * & -22.38369 & -24.41784^{*} \\ 7 & 1923.577 & 12.33727 & 5.81 \mathrm{e}-18 & -25.56731 & -21.60525 & -23.95723 \\ 8 & 1930.523 & 9.601525 & 7.84 \mathrm{e}-18 & -25.30181 & -20.80433 & -23.47415\end{array}$

* indicates lag order selected by the criterion

LR: sequential modified LR test statistic (each test at $5 \%$ level)

FPE: Final prediction error

AIC: Akaike information criterion

SC: Schwarz information criterion

HQ: Hannan-Quinn information criterion

Response to Cholesky One S.D. Innovations \pm 2 S.E.
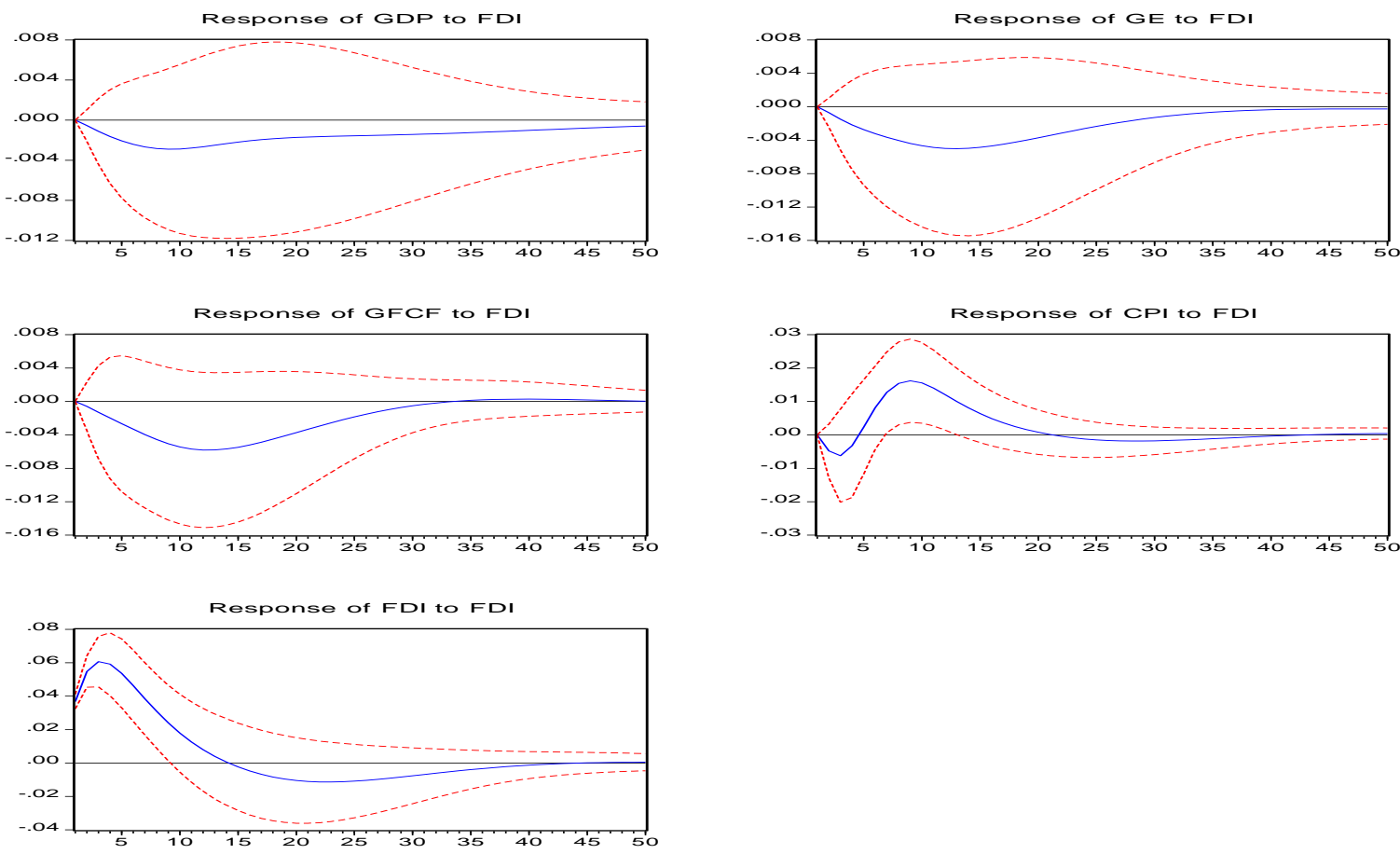

Figure 4: Impulse Response to Cholesky Decomposition 